\title{
Avaliação Econômica do Confinamento de Novilhos de Origem Leiteira, Alimentados com Diferentes Níveis de Concentrado e de Cama de Frango 1
}

\author{
Moacir Rodrigues Filho², Antônio Bento Mancio ${ }^{3}$, Sebastião Teixeira Gomes ${ }^{4}$, \\ Fabiano Ferreira da Silva ${ }^{5}$, Rogério de Paula Lana ${ }^{3}$, Nair Elizabeth Barreto Rodrigues ${ }^{2}$, \\ Carla Aparecida Soares ${ }^{6}$, Cristina Mattos Veloso ${ }^{5}$
}

\begin{abstract}
RESUMO - Foram confinados 24 bezerros mestiços Holandês x Zebu, machos não-castrados, com peso médio inicial de 75 $\mathrm{kg}$ e final de $215 \mathrm{~kg}$, com o objetivo de avaliar o custo de produção. Os animais foram alimentados com capim-elefante de 30 a 45 dias de idade, concentrado à base de farelo de soja, fubá de milho, farinha de carne, mistura mineral e cama de frango, sendo constituídos os tratamentos: $1=50 \%$ volumoso e $50 \%$ concentrado; $2=50 \%$ volumoso, $35 \%$ de concentrado e $15 \%$ de cama de frango; $3=25 \%$ de volumoso e $75 \%$ concentrado; e $4=25 \%$ de volumoso, $52,5 \%$ de concentrado e $22,5 \%$ de cama de frango, na base da matéria seca. O delineamento experimental foi em blocos casualisados, com seis repetições. A análise da renda bruta, dos custos e do lucro indicou que o lucro foi negativo em todos os tratamentos, quando o preço de venda da carne produzida foi igual ao preço do boi gordo. Entretanto, quando foram mantidos os mesmos custos (custo operacional efetivo e custo operacional total) e elevado em $10 \%$ o preço de venda do quilo de carne produzida, em relação ao preço do quilo de carne de boi gordo, todos os tratamentos apresentaram lucro, sendo destacados os tratamentos 2 e 3, com R $\$ 0,042$ e $\mathrm{R} \$ 0,03$ por quilo de carne produzida e retorno sobre capital investido de 14,20 e 14,64\%/ano, respectivamente. A variação no preço do concentrado, de $\mathrm{R} \$ 0,26$ a $0,20 /$ $\mathrm{kg}$, causou maior impacto no custo operacional efetivo do tratamento 3 e menor no tratamento 2, proporcionando lucro e retorno sobre capital o investido para todos os tratamentos, a partir da relação 7,62:1 entre preço do concentrado x preço da carne. As simulações mostraram que o tratamento 2 foi economicamente mais vantajoso, visto que gerou melhor relação custo/benefício para as condições do presente trabalho.
\end{abstract}

Palavras-chave: custo/benefício, lucro, mestiços, preço, retorno sobre capital investido

\section{Economic Evaluation of Feedlot Dairy Crossbred Bulls Fed Diets With Different Concentrate and Broiler Litter Levels}

\begin{abstract}
Twenty-four Holstein crossbred young bulls, with $75 \mathrm{~kg}$ initial average weight and $215 \mathrm{~kg}$ final average weight, were confined in a feedlot. The objective of this experiment was to evaluate the production cost. The animals were fed elephant grass with 30 to 45 days of age, soybean meal, corn meal, meat meal and mineral mix basal concentrate, and broiler litter, which constituted the treatments: $1=50 \%$ forage and $50 \%$ concentrate, $2=50 \%$ forage, $35 \%$ concentrate and $15 \%$ broiler litter, $3=25 \%$ forage and $75 \%$ concentrate and $4=25 \%$ forage, $52.5 \%$ concentrate and $22.5 \%$ broiler litter, as dry matter basis. It was used the completely randomized blocks experimental design, with six blocks and four treatments. The gross income, costs and profit analysis indicated that the profit was negative in all treatments when the produced meat sale price was the same as the fat ox price. However, when the same costs were maintained (effective operational cost and total operational cost) and the kilo of produced meat sale price rose $10 \%$, relative to the fat ox kilo of meat price, all the treatments presented profit, distinguishing the treatments 2 and 3, with $\mathrm{R} \$ 0.042$ and $\mathrm{R} \$ 0.03$ per kilo of produced meat and return on the invested capital of 14.20 and $14.64 \%$ /year, respectively. The concentrate price variation, from 0.26 to $0.20 \mathrm{R} \$ / \mathrm{kg}$, caused larger impact in the effective operational cost of treatment 3 and smaller in treatment 2, providing profit and return on the invested capital for all treatments, based on the 7.62:1 relationship between concentrate price $\mathrm{x}$ meat price. The simulations showed that treatment 2 was economically more advantageous because it produced a better cost/benefit relationship in the conditions of the present work.
\end{abstract}

Key Words: cost/benefit, crossbred, price, profit, return on the invested capital

\footnotetext{
${ }^{1}$ Parte da Dissertação apresentada à UFV pelo primeiro autor, para obtenção do título de Mestre. Financiado pela FAPEMIG. 2 Professor(a) da Escola Agrotécnica Federal de Santa Tereza, 29660-000 - Santa Tereza, ES. E.mail: moacirrf@escelsa.com.br 3 Professor do Departamento de Zootecnia da UFV, 36570-000 - Viçosa, MG.

${ }^{4}$ Professor do Departamento de Economia da UFV, 36570-000 - Vicosa, MG.

${ }^{5}$ Professor(a) do Departamento de Tecnologia Rural e Animal da UESB, 45700-000 - Itapetinga, BA. E.mail: ffsilva@uesb.br
} 


\section{Introdução}

Alguns trabalhos (Ribeiro, 1997; Signoretti et al., 1999) têm verificado que os bezerros provenientes de rebanhos leiteiros apresentam potencial para ganho de peso, em virtude de sua precocidade e eficiência alimentar, com bom rendimento e qualidade de carcaça. Entretanto, constata-se que a alimentação consiste no principal fator no custo de produção.

A exploração econômica destes animais deve ser fundamentada em uma série de estratégias que visem aumentar o ganho de peso, sem, contudo, onerar o custo de sua criação. Atualmente, busca-se o aproveitamento racional do macho leiteiro, pois, acreditase que possa contribuir substancialmente para o panorama econômico da pecuária nacional e para a oferta de carne mais regular, evitando as oscilações de preço e a ociosidade dos abatedouros.

Nos últimos trinta anos, a pesquisa agropecuária no Brasil tem gerado expressivo número de alternativas tecnológicas aplicáveis aos vários segmentos do setor produtivo, com efetivo incremento na produtividade (Anualpec, 2000). Por outro lado, não tem sido dada a devida importância aos aspectos econômicos desses novos processos, o que, a priori, parece ter reflexo direto na adoção de novas tecnologias. Isto sugere que tal fato decorre do princípio de que nem sempre uma tecnologia de produção que gera melhor desempenho, sob o ponto de vista produtivo, resulta em aumento de lucratividade, devido aos custos oriundos de sua implementação.

Poucos são os trabalhos que apresentam avaliações econômicas ou custo de produção de sistemas de criação de machos de origem leiteira. Ribeiro (1997) conduzindo trabalho com bezerros holandeses puros por cruza, abatidos com $200 \mathrm{~kg}$ de peso vivo (PV), entre 5-6 meses de idade, recebendo dietas com diferentes níveis de concentrado (45, 60, 75 e 90\%), associado com feno de coastcross, a partir de 75 dias de idade, constatou que os animais de todos os tratamentos apresentaram bom desempenho, indicando a viabilidade técnica do sistema. Por outro lado, houve inviabilidade econômica deste manejo, neste sistema, devendo ser contornada com novos estudos referentes à busca de alternativas para a alimentação dos animais, visando diminuir o gasto com a alimentação, sem que se comprometa o desempenho dos mesmos, já que o fator que mais limita a criação de machos de origem leiteira, em larga escala, como produtor de carne é, sem dúvida, o custo da alimentação.
O objetivo deste trabalho foi avaliar o custo de produção de novilhos de origem leiteira, em confinamento, alimentados com diferentes proporções de concentrado e de cama de frango na ração total.

\section{Material e Métodos}

O experimento foi realizado no Departamento de Zootecnia da Universidade Federal de Viçosa - MG, utilizando 24 bezerros machos não-castrados, mestiços e puros da raça Holandesa, com grau de sangue variando de $3 / 4$ a PC, com peso médio inicial de $75 \mathrm{~kg}$ de PV, oriundos da EMBRAPA-CNPGL, Coronel Pacheco - MG, e do rebanho leiteiro da UFV. Os animais foram mantidos em regime de confinamento, blocados por peso e distribuídos ao acaso entre quatro tratamentos, que compreenderam duas proporções de volumoso e duas proporções de cama de frango, conforme Tabela 1.

As rações foram constituídas de capim-elefante picado, com 30-45 dias de idade, como volumoso, e concentrado básico (86,64\% de fubá de milho, 13,07\% de farelo de soja, $5,85 \%$ de farinha de carne, $0,40 \%$ de sal comum, $0,02 \%$ de premix mineral e $0,08 \%$ de premix vitamínico) e cama de frango de capimelefante desintegrada.

A composição bromatológica do capim-elefante, do concentrado, da cama de frango e dos tratamentos é apresentada nas Tabelas 2 e 3 .

As rações foram calculadas com base nas exigências nutricionais do NRC (1989), para ganho de peso esperado de $0,8 \mathrm{~kg} \mathrm{PV} /$ dia.

Durante a fase experimental, o alimento foi fornecido no cocho à vontade duas vezes ao dia, procurando-se manter sobras em torno de $10 \%$ do peso total do alimento fornecido diariamente. Para deter-

Tabela 1 - Composição percentual dos tratamentos, na base da matéria seca

Table 1 - Treatments composition in dry matter base

\begin{tabular}{|c|c|c|c|c|}
\hline \multirow[t]{2}{*}{$\begin{array}{l}\text { Tratamentos } \\
\text { Treatments }\end{array}$} & \multicolumn{4}{|c|}{$\begin{array}{l}\text { Components } \\
\text { Componentes }\end{array}$} \\
\hline & $50: 0$ & $35: 15$ & $75: 0$ & $52,5: 22,5$ \\
\hline $\begin{array}{l}\text { Capim-elefante } \\
\text { Elephant grass }\end{array}$ & 50 & 50 & 25 & 25 \\
\hline $\begin{array}{l}\text { Concentrado básico } \\
\text { Basic concentrate }\end{array}$ & 50 & 35 & 75 & 52,5 \\
\hline $\begin{array}{l}\text { Cama de frango } \\
\text { Broiler litter }\end{array}$ & 0 & 15 & 0 & 22,5 \\
\hline
\end{tabular}


Tabela 2 - Composição química do capim-elefante, concentrado e cama de frango (\% da MS)

Table 2 - Chemical composition of elephant grass, concentrate and broiler litter (\% DM)

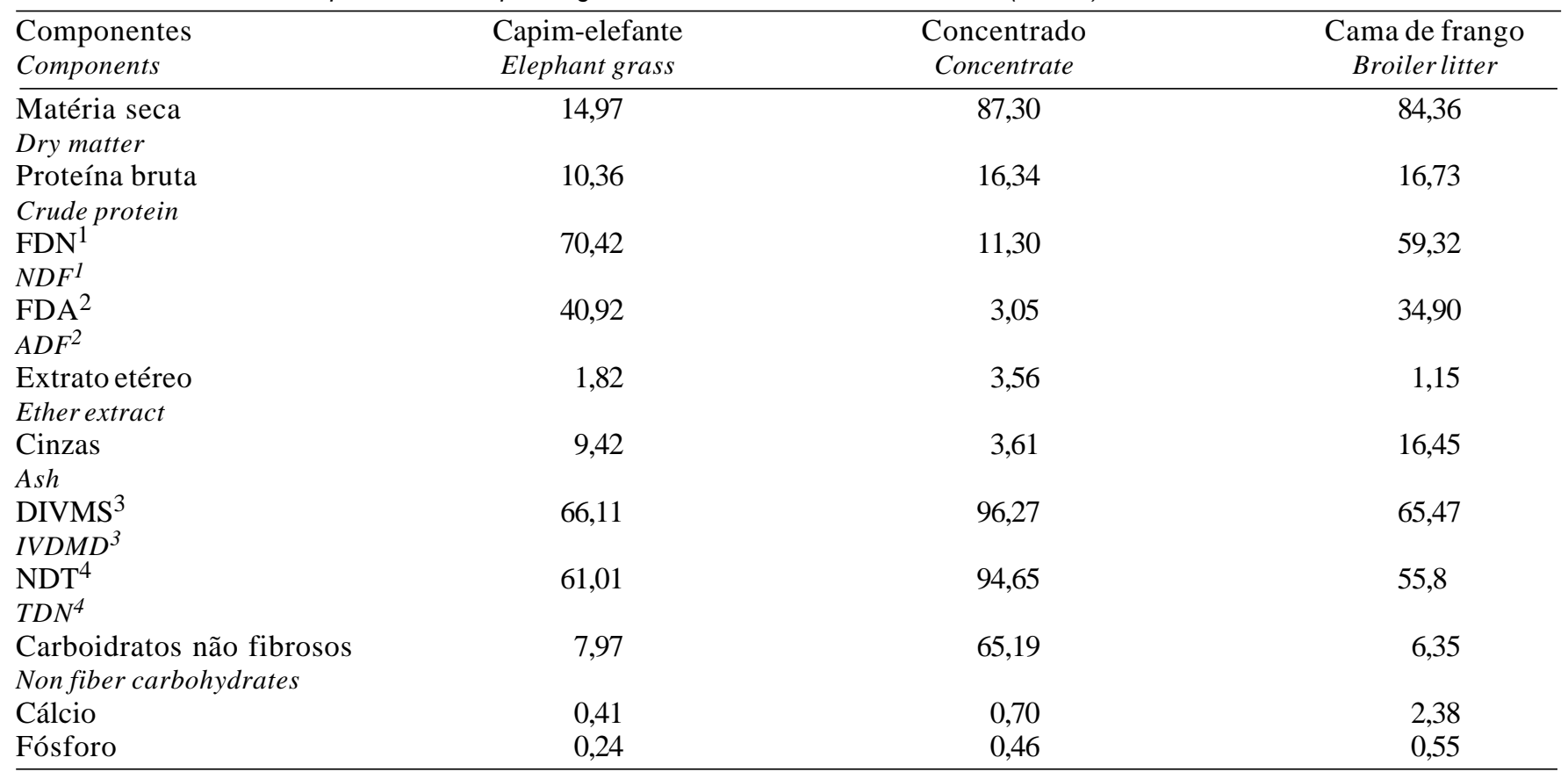

1 Fibra em detergente neutro (Neutral detergent fiber).

2 Fibra em detergente ácido (Acid detergent fiber).

3 Digestibilidade in vitro da matéria seca (In vitro dry matter digstibility).

${ }^{4}$ Nutrientes digestíveis totais (Valor estimado) (Total digestible nutrients [Estimated value]).

minar o consumo alimentar durante o período experimental, foi registrada diariamente a quantidade de ração completa ofertada e rejeitada.

Foi realizada uma pesagem dos animais no início do experimento e, periodicamente, a cada 28 dias para determinação do ganho de peso vivo. Os animais foram avaliados até atingirem os pesos médios preestabelecidos para abate de $215 \mathrm{~kg}$, tendo entrado no experimento com $75 \mathrm{~kg}$. Após o abate, as carcaças foram levadas à câmara fria a $5^{\circ} \mathrm{C}$ por, aproximadamente, 24 horas e, decorrido este tempo, as meiacarcaças foram pesadas para obtenção do peso de carcaça fria.

Os dados de consumo, ganho de peso, dias de confinamento e peso da carcaça fria foram analisados estatisticamente por meio de análise de variância. As médias foram comparadas pelo teste StudentNewman-Keuls, em nível de 5\% de probabilidade. Foi realizada análise de regressão polinomial entre o teor de FDN das dietas (variável independente) e o consumo de MS e o ganho médio diário (variáveis dependentes).

Foram considerados, para avaliação do custo de produção, a metodologia de custo operacional utilizada pelo IPEA (Matsunaga et al., 1976) e o critério de
Tabela 3 - Composição química dos tratamentos (\% da MS)

Table 3 - Treatments chemical composition (\% DM)

\begin{tabular}{|c|c|c|c|c|}
\hline \multirow[b]{2}{*}{$\begin{array}{l}\text { Componentes } \\
\text { Components }\end{array}$} & \multicolumn{4}{|c|}{$\begin{array}{c}\text { Tratamentos } \\
\text { Treatments }\end{array}$} \\
\hline & $50: 0$ & $35: 15$ & $75: 0$ & $52,5: 22,5$ \\
\hline $\begin{array}{l}\text { Matéria seca } \\
\text { Dry matter }\end{array}$ & 25,56 & 25,52 & 39,54 & 39,4 \\
\hline $\begin{array}{l}\text { Proteína bruta } \\
\text { Crude protein }\end{array}$ & 13,35 & 13,41 & 14,85 & 14,93 \\
\hline $\begin{array}{l}\mathrm{FDN}^{1}\left(N D F^{1}\right) \\
\operatorname{FDA}^{2}\left(A D F^{2}\right)\end{array}$ & $\begin{array}{l}40,86 \\
21,99\end{array}$ & $\begin{array}{l}48,10 \\
26,76\end{array}$ & $\begin{array}{l}26,08 \\
12,56\end{array}$ & $\begin{array}{l}36,88 \\
19,68\end{array}$ \\
\hline $\begin{array}{l}\text { Extrato etéreo } \\
\text { Ether extract }\end{array}$ & 2,69 & 2,33 & 3,1 & 2,58 \\
\hline $\begin{array}{l}\text { Cinzas }(A s h) \\
\text { DIVMS }^{3}\end{array}$ & $\begin{array}{r}6,25 \\
77,86\end{array}$ & $\begin{array}{r}8,44 \\
72,03\end{array}$ & $\begin{array}{c}5,1 \\
86,23\end{array}$ & $\begin{array}{r}7,95 \\
77,51\end{array}$ \\
\hline$I V D M D^{3}$ & & & & \\
\hline $\begin{array}{l}\mathrm{NDT}^{4} \\
T D N^{4}\end{array}$ & 81,19 & 76,56 & 88,72 & 81,79 \\
\hline $\begin{array}{l}\text { Carboidratos } \\
\text { não fibrosos } \\
\text { Non fiber } \\
\text { carbohydrates }\end{array}$ & 36,88 & 27,72 & 50,87 & 37,38 \\
\hline Cálcio & 0,56 & 0,81 & 0,63 & 1,00 \\
\hline Fósforo & 0,35 & 0,36 & 0,41 & 0,46 \\
\hline
\end{tabular}

${ }_{1}^{1}$ Fibra em detergente neutro (Neutral detergent fiber).

${ }^{2}$ Fibra em detergente ácido (Acid detergent fiber).

3 Digestibilidade in vitro da matéria seca (In vitro dry matter digstibility).

${ }^{4}$ Nutrientes digestíveis totais (Valor estimado) (Total digestible nutrients [Estimated value]).

\section{R. Bras. Zootec., v.31, n.5, p.2055-2069, 2002}


lucro e retorno sobre capital investido para análise econômica. Consideraram-se, como renda bruta, os valores correspondentes à venda do peso total das carcaças quentes ao final do experimento e à venda de esterco, cuja quantidade foi estimada a partir da indigestibilidade da matéria seca (MS) da ração total de cada tratamento, a preços de mercado, coletados no primeiro semestre de 1998, em Viçosa. Como custos, foram considerados os gastos e as despesas com alimentação, medicamentos, mão-de-obra, depreciação dos bens empregados no processo produtivo, impostos, juros e taxas bancárias. Consideram-se, como valor da mão-de-obra, o salário mínimo e os encargos sociais vigentes no primeiro semestre de 1998 , cujo valor foi de $\mathrm{R} \$ 198,00$. Os custos de insumos e serviços foram calculados multiplicandose as quantidades efetivamente utilizadas, pelos respectivos preços.

A depreciação de benfeitorias, máquinas, equipamentos e animais de serviço foi estimada pelo método linear de cotas fixas, com valor final igual a zero. Para a remuneração do capital, utilizou-se a taxa de juro real de $6 \%$ ao ano.

O custo da terra nua foi calculado multiplicando-se o seu preço pelo juro real de $6 \%$ ao ano. Considerouse, como gasto médio anual com reparos de benfeitoria e de máquinas e equipamentos, o equivalente a $1,5 \mathrm{e}$ $5,0 \%$, respectivamente, do valor mobilizado em benfeitorias e aquisição de máquinas e equipamentos (Gomes \& Novaes, 1992). O custo de formação e manutenção da capineira está incorporado no preço do quilo de matéria seca do capim-elefante a campo (Reis, 2000). O valor de venda do esterco foi transformado em equivalente carne, dividindo-se seu valor pelo preço do quilo de carne comercializada. Constam da Tabela 4 a forma de comercialização dos produtos e seus respectivos preços.

Nas Tabelas 5 e 6 são apresentados, respectivamente, de forma detalhada, os dados sobre preços de insumos e serviços, e a vida útil e o valor de benfeitoria, máquinas, equipamentos, animal de serviço e o valor da terra, utilizados no experimento. Nas Tabelas 7 e 8 , encontram-se suas respectivas quantidades utilizadas por bezerro e por tratamento.
Tabela 4 - Preço médio de venda dos produtos no primeiro semestre de 1998, no mercado de Viçosa

Table 4 - Products sale mean price at the first 1998 semester in Viçosa market

\begin{tabular}{lcc}
\hline $\begin{array}{l}\text { Produto } \\
\text { Product }\end{array}$ & $\begin{array}{c}\text { Unidade } \\
\text { Unit }\end{array}$ & $\begin{array}{c}\text { Valor unitário }(\mathrm{R} \$) \\
\text { Unit price }(R \$)\end{array}$ \\
\hline Carne & $\mathrm{kg}$ & 1,60 \\
$\begin{array}{l}\text { Meat } \\
\text { Esterco de curral }\end{array}$ & $\mathrm{t}$ & 35,00 \\
$(31,2 \% \mathrm{MS})$ & & \\
Manure $(31,2 \% \mathrm{DM})$ & & \\
\hline
\end{tabular}

Tabela 5 - Preços de insumos e serviços utilizados no experimento

Table 5 - Inputs and services prices used in the experiment

\begin{tabular}{|c|c|c|}
\hline $\begin{array}{l}\text { Discriminação } \\
\text { Discrimination }\end{array}$ & $\begin{array}{c}\text { Unidade } \\
\text { Unit }\end{array}$ & $\begin{array}{c}\text { Preço unitário }(\mathrm{R} \$) \\
\text { Unit price }(R \$) \\
\end{array}$ \\
\hline $\begin{array}{l}\text { Concentrado básico } \\
\text { Basic concentrate }\end{array}$ & $\begin{array}{l}\mathrm{kg} \text { de } \mathrm{MS}, \\
\mathrm{kg} \text { of } \mathrm{DM}\end{array}$ & 0,26 \\
\hline $\begin{array}{l}\text { Cama de frango } \\
\text { Broiler litter }\end{array}$ & $\begin{array}{l}\mathrm{kg} \text { de } \mathrm{MS}, \\
\mathrm{kg} \text { of } D M\end{array}$ & 0,07 \\
\hline $\begin{array}{l}\text { Capim-elefante } \\
\text { Elephant grass }\end{array}$ & $\begin{array}{l}\mathrm{kg} \text { de } \mathrm{MS}, \\
\mathrm{kg} \text { of } D M\end{array}$ & 0,02339 \\
\hline $\begin{array}{l}\text { Vermífugo } \\
\text { Vermifuge }\end{array}$ & $\mathrm{mL}$ & 0,24 \\
\hline $\begin{array}{l}\text { Carrapaticida } \\
\text { Drug againts tick }\end{array}$ & $\mathrm{mL}$ & 0,07 \\
\hline $\begin{array}{l}\text { Vacina de aftosa } \\
\text { Aftosa vaccine }\end{array}$ & dose & 0,43 \\
\hline $\begin{array}{l}\text { Vacina de C.sintomático } \\
\text { Clostridium vaccine }\end{array}$ & dose & 0,14 \\
\hline $\begin{array}{l}\text { ADE injetável } \\
\text { ADE vitamin }\end{array}$ & $\mathrm{mL}$ & 0,096 \\
\hline $\begin{array}{l}\text { Seringa } \\
\text { Syringe }\end{array}$ & un & 2,4 \\
\hline $\begin{array}{l}\text { Agulha } \\
\text { Needle }\end{array}$ & un & 0,7 \\
\hline $\begin{array}{l}\text { Iodo } \\
\text { Iodine }\end{array}$ & $\mathrm{mL}$ & 0,012 \\
\hline $\begin{array}{l}\text { Lepecid } \\
\text { Álcool }\end{array}$ & $\begin{array}{l}\mathrm{mL} \\
\mathrm{mL}\end{array}$ & $\begin{array}{c}0,0052 \\
0,001\end{array}$ \\
\hline $\begin{array}{l}\text { Alcohool } \\
\text { Energia }\end{array}$ & $\mathrm{KW} / \mathrm{h}$ & 0,11 \\
\hline $\begin{array}{l}\text { Electric power } \\
\text { Mão-de-obra } \\
\text { Labor }\end{array}$ & $\mathrm{d} / \mathrm{H}$ & 6,6 \\
\hline
\end{tabular}


Tabela 6 - Vida útil e valor de benfeitoria, máquinas, equipamentos, animal e terra

Table 6 - Improvement, machines, equipments, animals and earth useful life and price

\begin{tabular}{lrr}
\hline $\begin{array}{l}\text { Discriminação } \\
\text { Discrimination }\end{array}$ & $\begin{array}{c}\text { Vida útil (dias) } \\
\text { Useful life (days) }\end{array}$ & $\begin{array}{r}\text { Valor de mercado (R \$) } \\
\text { Market price }\end{array}$ \\
\hline Balança de curral - 1500 kg (Scale for cattle - 1500 kg) & 5475 & $2.638,13$ \\
Balança de braço - 300 kg (Scale - 300 kg) & 3650 & 274,00 \\
Picadeira NPP 47 (Grass cutting machine NPP 47) & 3650 & $1.599,00$ \\
Pulverizador costal 20 L (Costal pulverizer 20 L) & 62,50 \\
Carroça de tração animal (Coach) & 1825 & 800,00 \\
Arreios de animal de tração (Harness) & 3650 & 150,00 \\
Galpão de confinamento (Feedlot hangar) & 1095 & $6.000,00$ \\
Facão para cana (Large knife) & 5475 & 5,20 \\
Garfo de quatro dentes (Four teeth fork) & 730 & 12,00 \\
Pá de bico (Shovel) & 730 & 6,10 \\
Utilidades de pequeno valor (Small value utilities) & 730 & 35,30 \\
Animal de serviço - Eqüino (Equine) & 730 & 250,00 \\
Terra nua (R\$/ha) (Earth) & 5475 & 1600,00 \\
Capital fixo investido R\$ (Fixed capital invested $R \$$ ) & & $13.432,23$ \\
\hline
\end{tabular}

${ }^{1}$ Fontes: OCB, Ocepar, EMBRAPA, CFP e Secretaria da Agricultura do Estado de São Paulo - Informação pessoal.

${ }^{1}$ Source: OCB, Ocepar, EMBRAPA, CFP and Agriculture Clerkship of São Paulo State - Personal information.

Tabela 7 - Quantidades de insumos e serviços utilizados por bezerro e por tratamento Table 7 - Amounts of inputs and services used by calf and for treatment

\begin{tabular}{|c|c|c|c|c|c|}
\hline \multirow[t]{2}{*}{ Item } & \multirow[t]{2}{*}{$\begin{array}{l}\text { Unidade } \\
\text { Unit }\end{array}$} & \multicolumn{4}{|c|}{$\begin{array}{l}\text { Tratamentos } \\
\text { Treatments }\end{array}$} \\
\hline & & 50:0 & $35: 15$ & $75: 0$ & $52,5: 22,5$ \\
\hline $\begin{array}{l}1 \text { - Mão-de-obra } \\
1 \text { - Labor } \\
2 \text { - Alimentação } \\
2 \text { - Feeding }\end{array}$ & $\mathrm{d} / \mathrm{H}$ & 3,79 & 3,90 & 2,92 & 3,32 \\
\hline $\begin{array}{l}\text { Concentrado básico } \\
\text { Basic concentrate }\end{array}$ & $\mathrm{kg}$ de $\mathrm{MS}$ & 317,405 & 226,345 & 407,775 & 312,6532 \\
\hline $\begin{array}{l}\text { Cama de frango } \\
\text { Broiler litter }\end{array}$ & $\mathrm{kg}$ de MS & 0 & 97,005 & 0 & 133,9942 \\
\hline $\begin{array}{l}\text { Capim-elefante } \\
\text { Elephante grass }\end{array}$ & $\mathrm{kg}$ de $\mathrm{MS}$ & 317,405 & 323,35 & 135,925 & 148,982 \\
\hline $\begin{array}{l}3 \text {-Energia } \\
3 \text {-Electric power } \\
4 \text { - Medicamentos } \\
4 \text {-Medicines }\end{array}$ & $\mathrm{KW} / \mathrm{h}$ & 2,07 & 8,86 & 0,9 & 10,54 \\
\hline $\begin{array}{l}\text { Vermífugo } \\
\text { Vermifuge }\end{array}$ & $\mathrm{mL}$ & 3,58 & 4,5 & 5 & 4 \\
\hline $\begin{array}{l}\text { Carrapaticida } \\
\text { Drug againts tick }\end{array}$ & $\mathrm{mL}$ & 4 & 4 & 4 & 4 \\
\hline $\begin{array}{l}\text { Vacina aftosa } \\
\text { Aftosa vaccine }\end{array}$ & dose & 1 & 1 & 1 & 1 \\
\hline $\begin{array}{l}\text { Vacina C. sintomático } \\
\text { Clostridium vaccine }\end{array}$ & dose & 1 & 1 & 1 & 1 \\
\hline $\begin{array}{l}\text { ADE injetável } \\
A D E \text { vitamin }\end{array}$ & $\mathrm{mL}$ & 1,5 & 1,5 & 1,5 & 1,5 \\
\hline $\begin{array}{l}\text { Seringa } \\
\text { Syringe }\end{array}$ & un & 0,084 & 0,084 & 0,084 & 0,084 \\
\hline $\begin{array}{l}\text { Agulha } \\
\text { Needle }\end{array}$ & un & 0,084 & 0,084 & 0,084 & 0,084 \\
\hline $\begin{array}{l}\text { Iodo } \\
\text { Iodine }\end{array}$ & $\mathrm{mL}$ & 10 & 10 & 10 & 10 \\
\hline Lepecid & $\mathrm{mL}$ & 10 & 10 & 10 & 10 \\
\hline $\begin{array}{l}\text { Álcool } \\
\text { Alcohol }\end{array}$ & $\mathrm{mL}$ & 50 & 50 & 50 & 50 \\
\hline
\end{tabular}


Tabela 8 - Tempo de uso de máquinas, equipamentos, benfeitorias, animais de tração e terra por bezerro e por tratamento

Table 8 - Machines, equipments, improvements, traction animals and earth used time per calf and per treatment

\begin{tabular}{|c|c|c|c|c|c|}
\hline \multirow[t]{2}{*}{$\begin{array}{l}\text { Discriminação } \\
\text { Discrimination }\end{array}$} & \multirow[t]{2}{*}{$\begin{array}{c}\text { Unidade } \\
\text { Unit }\end{array}$} & \multicolumn{4}{|c|}{$\begin{array}{l}\text { Tratamentos } \\
\text { Treatments }\end{array}$} \\
\hline & & $50: 0$ & $35: 15$ & $75: 0$ & $52,5: 22,5$ \\
\hline \multicolumn{6}{|l|}{$\begin{array}{l}1 \text { - Máquinas e equipamentos } \\
1 \text {-Machines and equipments }\end{array}$} \\
\hline $\begin{array}{l}\text { Balança de curral } 1500 \mathrm{~kg} \\
\text { Scale for cattle - } 1500 \mathrm{~kg}\end{array}$ & $\begin{array}{l}\text { dias } \\
\text { days }\end{array}$ & 0,01 & 0,01 & 0,0086 & 0,0086 \\
\hline $\begin{array}{l}\text { Balança de braço } 300 \mathrm{~kg} \\
\text { Scale - } 300 \mathrm{~kg}\end{array}$ & $\begin{array}{l}\text { dias } \\
\text { days }\end{array}$ & 0,27 & 0,28 & 0,21 & 0,23 \\
\hline $\begin{array}{l}\text { Pulverizado costal } 20 \mathrm{~L} \\
\text { Costal pulverizer } 20 \mathrm{~L}\end{array}$ & $\mathrm{hs}$ & 0,166 & 0,166 & 0,166 & 0,166 \\
\hline $\begin{array}{l}\text { Picadeira NPP } 47 \\
\text { Grass cutting machine NPP } 47\end{array}$ & $\mathrm{hs}$ & 1,11 & 1,13 & 0,48 & 0,52 \\
\hline $\begin{array}{l}\text { Facão para cana } \\
\text { Large knife }\end{array}$ & hs & 2,22 & 2,26 & 0,96 & 1,04 \\
\hline $\begin{array}{l}\text { Garfo de } 4 \text { dentes } \\
\text { Four teeth fork }\end{array}$ & $\mathrm{hs}$ & 0,33 & 0,34 & 0,14 & 0,16 \\
\hline $\begin{array}{l}\text { Pá de bico } \\
\text { Shovel }\end{array}$ & $\mathrm{hs}$ & 3,62 & 3,65 & 2,66 & 2,91 \\
\hline $\begin{array}{l}\text { Utilitários de pequeno valor } \\
\text { Small value utilities }\end{array}$ & hs & 0,11 & 0,11 & 0,05 & 0,05 \\
\hline $\begin{array}{l}\text { Arreios de animal de tração } \\
\text { Harness }\end{array}$ & $\begin{array}{l}\text { dias } \\
\text { days }\end{array}$ & 0,159 & 0,154 & 0,133 & 0,136 \\
\hline $\begin{array}{l}\text { Carroça de tração animal } \\
\text { Coach }\end{array}$ & $\begin{array}{l}\text { dias } \\
\text { days }\end{array}$ & 0,159 & 0,154 & 0,133 & 0,136 \\
\hline \multicolumn{6}{|l|}{$\begin{array}{l}2 \text { - Benfeitorias } \\
2 \text { - Improvements }\end{array}$} \\
\hline $\begin{array}{l}\text { Galpão de confinamento } \\
\text { Feedlot hangar }\end{array}$ & $\begin{array}{l}\text { dias } \\
\text { days }\end{array}$ & 6,58 & 6,62 & 5,04 & 5,5 \\
\hline \multicolumn{6}{|l|}{$\begin{array}{l}3-\text { Animal } \\
3 \text { - Animal }\end{array}$} \\
\hline $\begin{array}{l}\text { Eqüino } \\
\text { Equine }\end{array}$ & $\begin{array}{l}\text { dias } \\
\text { days }\end{array}$ & 0,159 & 0,154 & 0,133 & 0,136 \\
\hline $\begin{array}{l}\text { 4- Terra } \\
4 \text { - Earth }\end{array}$ & ha & 0,245 & 0,245 & 0,245 & 0,245 \\
\hline
\end{tabular}

\section{Resultados e Discussão}

Os resultados de desempenho, como consumo, ganho de peso, dias de confinamento, peso de abate, peso da carcaça fria, quantidade de carne produzida e rendimentos de carcaça e de carne são apresentados na Tabela 9. Quando expresso em $\mathrm{kg} / \mathrm{dia}$, o consumo de MS não foi influenciado $(\mathrm{P}>0,05)$ pelo nível de concentrado e pelo nível de cama de frango. Vários trabalhos na literatura relataram influência positiva dos níveis de concentrado sobre o consumo de MS (Araújo et al., 1998; Ferreira et al., 1999). Possivelmente, isto não ocorreu neste experimento, pois, as dietas com menor participação de concentrado (50:0 e 35:15) já propiciaram baixos consumos de
FDN (< 1\% PV), não causando restrições físicas de consumo. Os níveis de FDN da dieta não influenciaram $(\mathrm{P}>0,05)$ o consumo de MS, apresentando valor médio de 4,28 kg/dia. Mesmo não existindo diferenças no consumo de MS entre os tratamentos, os animais que receberam as dietas com menor participação de volumoso (25\%) apresentaram maiores ganhos de PV e, conseqüentemente, permaneceram menos dias no confinamento para atingirem o mesmo $\mathrm{PV}$ que os animais dos tratamentos com 50\% de volumoso na dieta. Isso se explica pelo maior valor energético das dietas com maior participação de concentrado e, conseqüentemente, menores teores de FDN. O teor de FDN da dieta teve efeito linear negativo $(\mathrm{P}<0,05)$ sobre o ganho médio diário (GMD 
Tabela 9 - Consumo médio de matéria seca (CMS), expresso em kg/dia, ganho de peso diário (GMD), dias de confinamento $(D C)$, peso de abate $(P A)$, peso da carcaça fria (PCF), rendimento de carcaça fria $(R C F)$, peso da carne produzida (PCP) e rendimento de carne (RCAR)

Table 9 - Mean dry matter intake (DMI), in kg/day, daily body weight gain (BWG), days in feedlot, slaughter body weight (SBW), cold carcass weight (CCW), dressing percentage (DP), meat weight (MW) and meat percentage (MP)

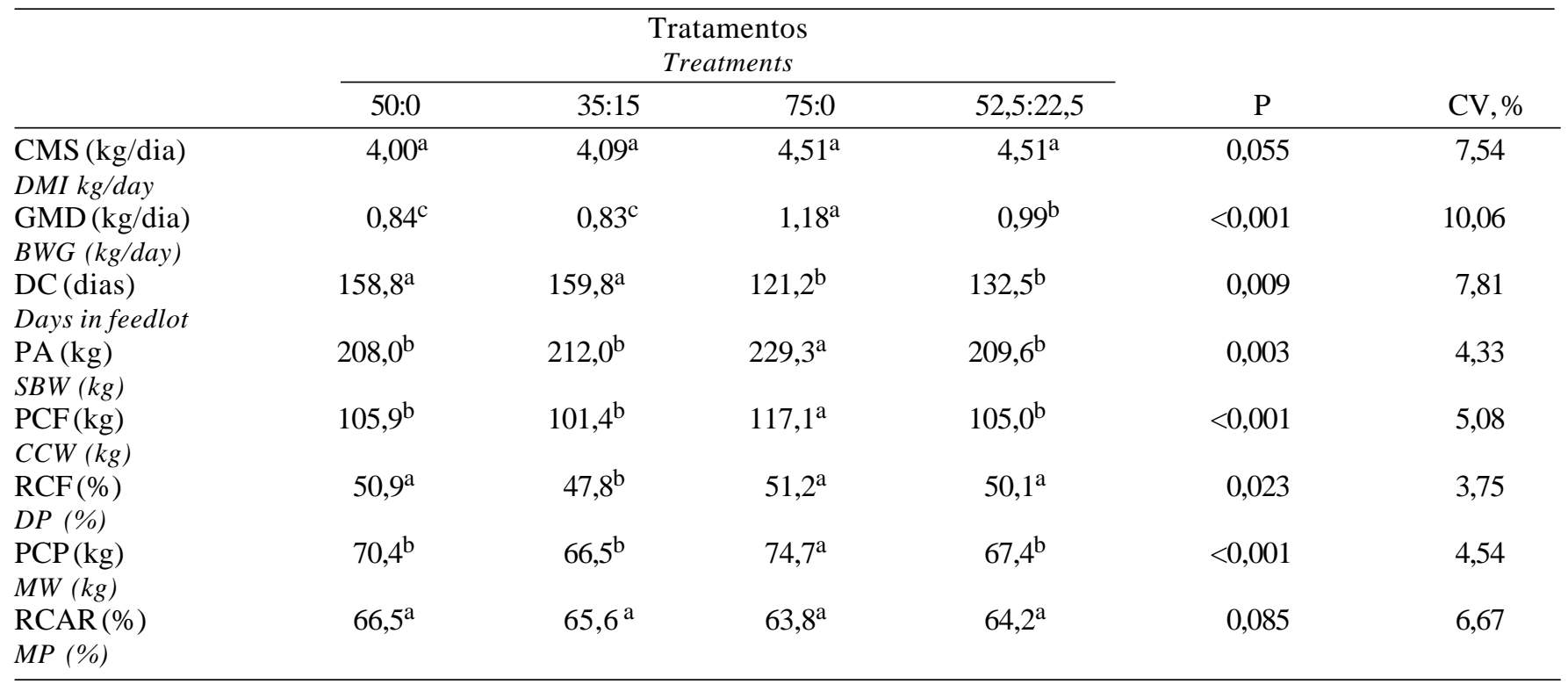

Médias na mesma linha, seguidas de uma mesma letra, não diferem pelo teste de Student-Newman-Keuls (5\%).

Means, within a row, followed by the same letters do not differ by Student-Newman-Keuls test (5\%).

$=1,6047-0,0169 \times \%$ FDN da dieta; $\left.\mathrm{r}^{2}=0,65\right)$. Nos tratamentos com relação volumoso:concentrado de 50:50, a inclusão de $15 \%$ de cama de frango não afetou o desempenho. Mas, nos tratamentos com relações volumoso:concentrado de 25:75, a inclusão de $22,5 \%$ de cama de frango na dieta total acarretou menores ganho de peso, peso de abate, peso de carcaça fria e peso de carne produzida, provavelmente devido ao menor consumo de energia desta dieta, uma vez que a cama de frango apresenta quase $60 \%$ de FDN. O rendimento de carcaça fria foi menor no tratamento com $15 \%$ de cama de frango, possivelmente porque esta dieta possuía um maior teor de FDN $(48,1 \%)$, o que pode ter levado a um aumento do peso e do conteúdo do trato gastrintestinal. Já o rendimento de carne produzida não foi afetado pelos tratamentos.

Os custos de produção e os resultados econômicos (renda bruta, custos, lucros e retorno sobre o capital investido), por tratamento e por bezerro, são apresentados na Tabela 10.

Observou-se, por meio da análise econômica, que todos os tratamentos apresentaram resultados negativos, notadamente o tratamento com $22,5 \%$ de cama de frango, que proporcionou maior prejuízo, seguido dos tratamentos que não continham cama de frango, com resultados semelhantes e intermediários, e o tratamento com $15 \%$ de cama de frango, com menor prejuízo. Contudo, quando se analisam a composição da renda e o comportamento dos custos, estes apresentam características distintas.

O tratamento com $75 \%$ de concentrado básico apresentou renda bruta $9,07 \%$ superior à média da renda dos outros tratamentos, devido à maior quantidade de unidade de carne $(9,7 \%)$ disponibilizada para venda e aos menores gastos com mão-de-obra, energia, depreciação e juros. Contrariamente, o tratamento com $15 \%$ de cama de frango apresentou menor renda bruta $(5,6 \%)$, em relação à média dos outros tratamentos, devido à menor quantidade $(6,86 \%)$ de unidade de carne disponibilizada para comercialização, associada aos maiores gastos com mão-de-obra, energia, depreciação e juros.

A comercialização do esterco incorporou valores à renda bruta da ordem de 3,$0 ; 3,7 ; 1,6 ;$ e $2,4 \%$ para os tratamentos 50:0, 35:15, 75:0 e 52,5:22,5, respectivamente.

Os custos operacionais efetivos (COE) representaram gastos da ordem de 94,5; 94,0; 96,0; e 95,0\% do custo total de produção para os tratamentos 50:0, $35: 15,75: 0$ e 52,5:22,5, respectivamente, sendo maior no tratamento com $75 \%$ de concentrado básico e

R. Bras. Zootec., v.31, n.5, p.2055-2069, 2002 
RODRIGUES FILHO et al.

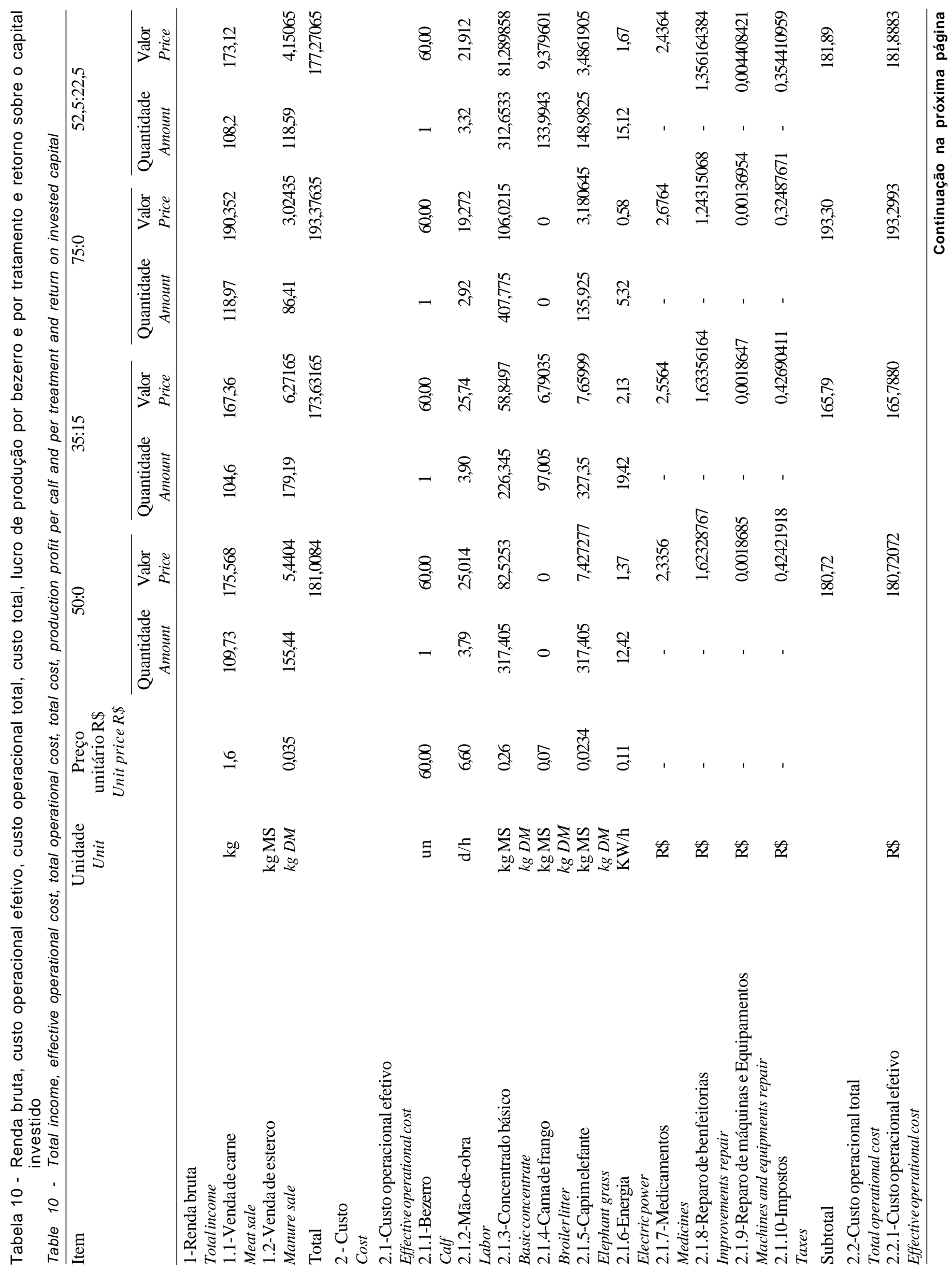




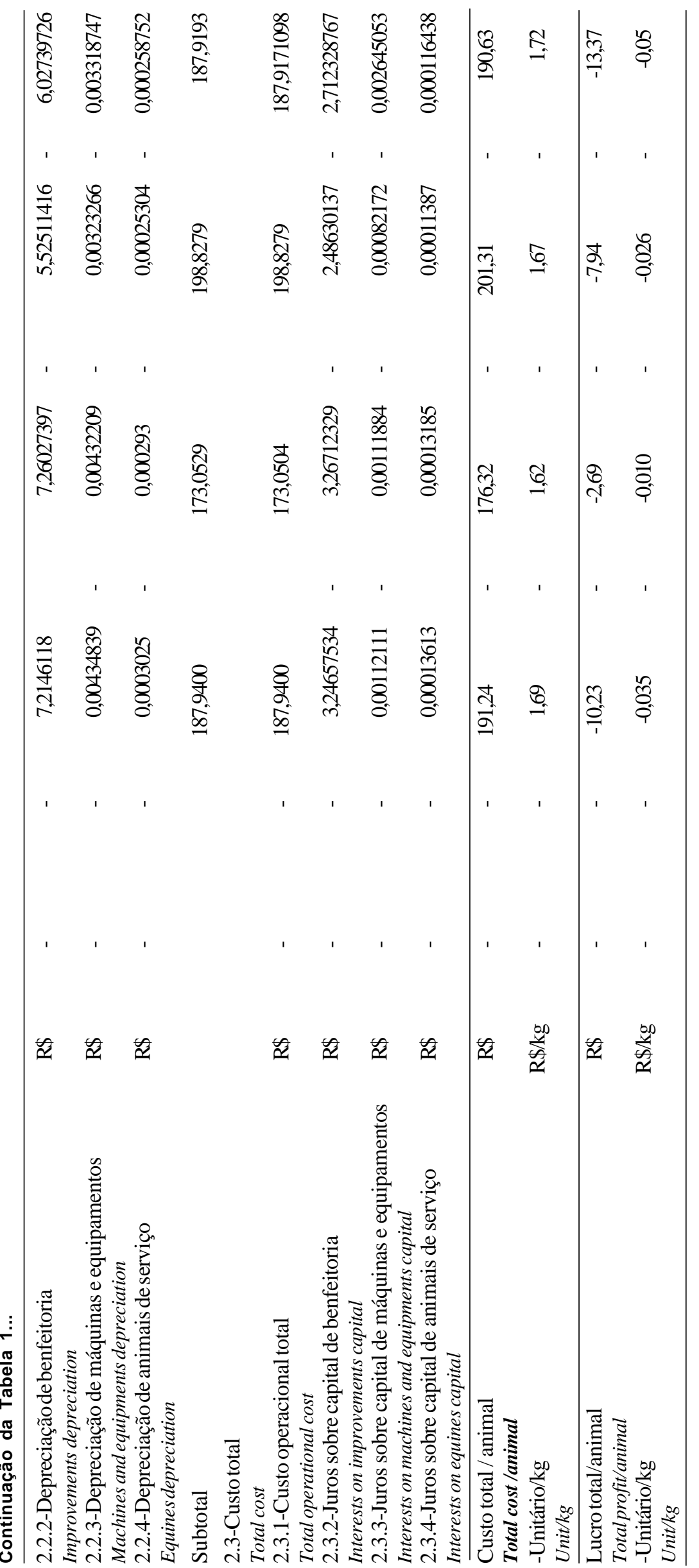


menor no tratamento com $15 \%$ de cama de frango, em relação à média dos outros tratamentos, devido, em parte, aos maiores e menores gastos com concentrado, respectivamente. Destacam-se também, nesta categoria de custos, os gastos com energia na elaboração da ração total dos tratamentos que continham cama de frango, decorrente, principalmente, do processamento da cama de frango. Esta prática agrega valores acima de $95 \%$ por quilo de MS de cama de frango, considerando os valores pagos neste experimento.

Os gastos indiretos com depreciações e juros foram maiores para os tratamentos com maior participação de volumoso na dieta, com menores taxas de ganho de peso diário e maior tempo no confinamento, e menores para os tratamentos com menor participação de volumoso na dieta, com maiores taxas de ganho e menor tempo no confinamento. Por outro lado, maiores dispêndios com gastos diretos foram observados nos tratamentos com $25 \%$ de volumoso, com maiores proporções de concentrado e cama de frango na ração total, indicando, neste caso, necessidade de maior volume de recursos em caixa para capital de giro. Assim, pode-se inferir que, em planos nutricionais mais elevados, para uma mesma escala de produção, os custos indiretos são reduzidos, enquanto os custos diretos são majorados. Entretanto, a decisão em optar por maior ou menor taxa de ganho médio diário, cujo reflexo recai sobre os custos diretos e indiretos, está condicionada à melhor relação custo-benefício.

Verificou-se ainda que, para a produção dos 24 bezerros, o custo fixo médio por animal, decorrente do capital médio mobilizado em infra-estrutura, foi de $\mathrm{R} \$ 279,84$. No entanto, se for mantida a mesma estrutura e elevar para 48 o número de animais, o que é operacionalmente possível, visto que o maior período de confinamento foi de 159 dias, o custo fixo médio por animal reduz em, no mínimo, $50 \%$, caindo para $\mathrm{R} \$ 139,92$. Isso indica que a escala de produção é importante parâmetro a ser considerado na eficiência econômica deste sistema de produção, não somente pela redução destes custos, em decorrência do aumento da produção, mas também pelo reflexo direto no preço de aquisição dos insumos.

O custo total por quilo de carne produzida foi semelhante para os animais dos tratamentos 50:0, 75:0 e 52,5:22,5, variando de $\mathrm{R} \$ 1,69$ a R $\$ 1,72$, e 5,0\% menor para o tratamento $35: 15$, gerando maiores valores negativos. Entretanto, o custo operacional total médio foi estatisticamente $(\mathrm{P}<0,01)$ superior $(10,7 \%)$ para os respectivos tratamentos, acarretando maior dispêndio financeiro.

Na Figura 1, é apresentada a participação percentual de cada componente no custo total de produção. Em ordem de importância, verificam-se a alimentação, o preço do bezerro, a mão-de-obra, outros (juro, reparos e depreciação) e os insumos veterinários.

A alimentação representou, em média, 48,8\% do custo total de produção, variando de 42,78 a $54,53 \%$, em função da proporção volumoso:concentrado, da cama de frango e da energia gasta no preparo da ração total. Esse gasto foi 10,4; 14,9; e 21,5\% menor para o tratamento 35:15 em relação aos tratamentos 50:0, 52,5:22,5 e 75:0, respectivamente.

A proporção de $15 \%$ de cama de frango na MS da ração total proporcionou redução de $10,4 \%$ nos gastos com alimentação, comparado ao tratamento 50:0, e a proporção de $22,5 \%$ de cama de frango redução de 7,8\%, comparado ao tratamento 75:0. Esta redução nos custos, apesar de expressiva, quando associada ao desempenho dos animais submetidos aos referidos tratamentos, não foi suficiente para gerar lucros e viabilizar economicamente a atividade.

O impacto do valor do bezerro no custo total de produção correspondeu, em média, a $31,7 \%$, sendo maior no tratamento com $15 \%$ de cama de frango $(12,1 \%)$, em relação ao tratamento com $75 \%$ de concentrado básico, e praticamente igual aos demais tratamentos (50:0 e 52,5:22,5). Este comportamento

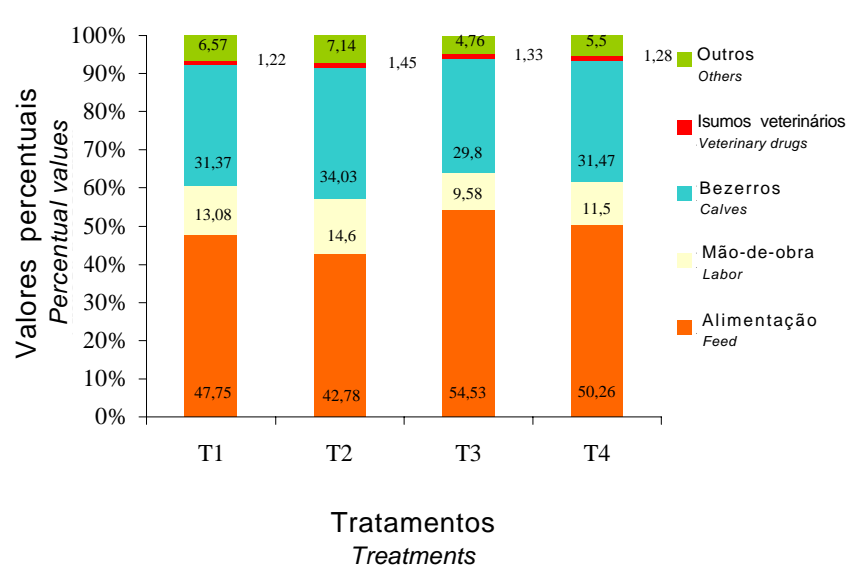

Figura 1 - Participação percentual dos componentes no custo de produção.

Figure 1 - Percentual participation of the itens in the production cost. 
pode ser atribuído ao fato do valor do bezerro estar negativamente correlacionado ao custo de produção.

Os menores gastos com mão-de-obra, juros, depreciações, reparos e insumos veterinários, verificados no tratamento com $75 \%$ de concentrado básico, estão diretamente relacionados ao menor tempo de confinamento dos animais deste tratamento, que proporcionou menores demandas desses componentes.

Como pode ser observado na Tabela 10, o custo por quilo de carne produzida em todos os tratamentos foi superior ao preço do quilo de carne pago ao produtor, gerando prejuízos, indicando, portanto, limitação de ordem econômica. Este fato aponta para a necessidade de se buscarem alternativas de mercado que valorizem a qualidade do produto oriundo deste sistema de produção, como incentivo ao produtor, visto que estes animais apresentam potencial para ganhar peso com eficiência alimentar e qualidade de carcaça superior, quando abatidos em idade precoce (Campos et al., 1996; Ribeiro, 1997).

Entre as possíveis alternativas, o pagamento diferenciado por quilo de carne produzida, em relação ao preço do quilo de carne do boi gordo, representa uma alternativa viável. Constam da Tabela 11 os resultados do estudo, no qual foi simulada apenas a variação no preço do quilo da carne, cuja referência foi o valor da situação real da pesquisa, e mantido o custo de produção inalterado.

Nota-se que, apesar da variação no preço da carne ter sido igual para todos os tratamentos, o maior impacto na renda bruta recaiu sobre o tratamento com $75 \%$ de concentrado, que superou em 10 pontos percentuais a média da renda dos outros tratamentos, quando o maior índice de correção foi considerado. Entretanto, o tratamento com $15 \%$ de cama de frango, com renda bruta $11 \%$ inferior ao do tratamento com $75 \%$ de concentrado básico, proporcionou lucro por animal muito semelhante ( $\mathrm{R} \$ 30,78$ e $\mathrm{R} \$ 30,13$ respectivamente) e lucro de $13,2 \%$ superior por quilo de carne produzida. A maior renda bruta no tratamento 75:0 e o maior lucro no tratamento 35:15 decorreram da maior produção obtida no primeiro e do menor custo de produção do segundo.

Verifica-se ainda que, a partir do acréscimo de $10 \%$ sobre o preço do quilo da carne do boi gordo, todos os tratamentos apresentaram resultados positivos, com pequena margem de lucro variando entre $\mathrm{R} \$ 3,95$ e $\mathrm{R} \$ 14,04$ por animal e $\mathrm{R} \$ 0,01$ e $\mathrm{R} \$ 0,042$ por quilo comercializável; notadamente o tratamento com $15 \%$ de participação da cama de frango na dieta total, que já a partir deste índice proporcionou lucro compatível com atividades afins no setor pecuário. $\mathrm{O}$ lucro por unidade de carne produzida, acrescido de $20 \%$ do valor referência $(\mathrm{R} \$ 1,6)$, foi de 0,$06 ; 0,077$; 0,068; e 0,05 reais para os tratamentos 50:0, 35:15, 75:0 e 52,5:22,5, respectivamente, destacando-se os animais submetidos ao tratamento $35: 15$, com lucro $30 \%$ superior à média de lucro dos animais submetidos aos demais tratamentos, previsivelmente devido aos menores custos deste tratamento. Com base nestes dados, pode-se inferir que o lucro alcançado em cada tratamento foi satisfatório, quando comparado com a margem de lucro na atividade leiteira, cujo valor gira em torno de $\mathrm{R} \$ 0,03$ a $\mathrm{R} \$ 0,07$ por quilo de leite produzido, dependendo do sistema de produção.

A Figura 2 apresenta o comportamento do retorno sobre capital investido (RSCI) ao ano por bezerro e por tratamento, em função da variação do preço da arroba do bezerro em relação ao preço da arroba do boi gordo. Nota-se que, no nível de 5\%, apesar de inexpressivos do ponto de vista de lucratividade, apenas os tratamentos 35:15 e 75:0 apresentaram retornos positivos, com 7,34 e 4,38\% ao ano, respectivamente. Já em nível de $10 \%$, todos os tratamentos proporcionaram RSCI superior à taxa real de juros da

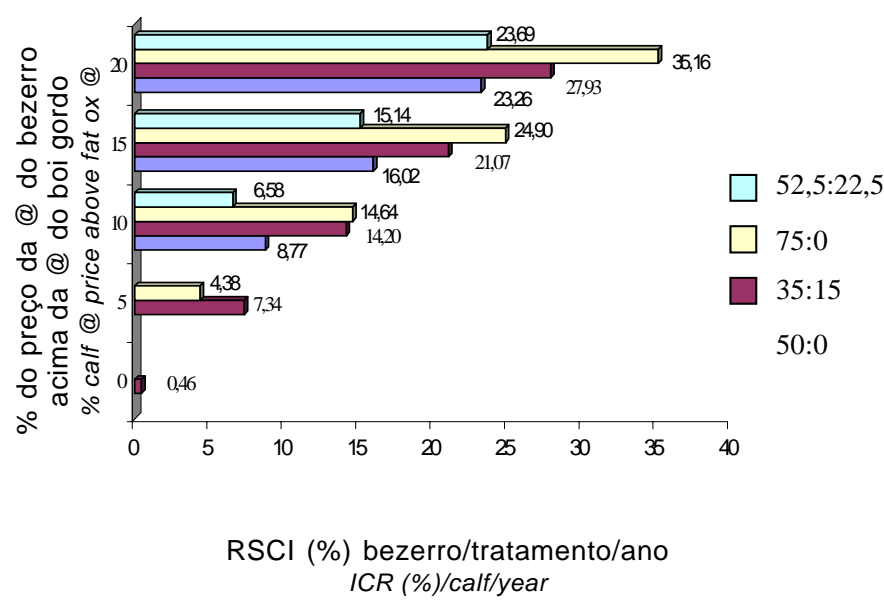

Figura 2 - Variação no preço da arroba da carne do bezerro, em relação ao preço da arroba da carne do boi gordo, e seu efeito no retorno sobre o capital investido.

Figure 2 - Variation in the calf meat price, in relation to the fat ox meat price and its effect in the invested capital return.

R. Bras. Zootec., v.31, n.5, p.2055-2069, 2002 
caderneta de poupança - média de $11 \%$ ao ano, o que possibilitou lucro médio de $\mathrm{R} \$ 0,026$ por quilo de carne produzida, margem considerada baixa. O RSCI como remuneração do capital investido na atividade passa a ser atrativo a partir de 21,$07 ; 24,90 ; 23,26$; e $23,69 \%$, gerando lucros por unidade de carne produzida de 0,$061 ; 0,050 ; 0,050 ; \mathrm{e} 0,050$ reais, decorrentes dos acréscimos de $15,15,20$ e $20 \%$ na arroba do bezerro para os tratamentos 35:15, 75:0, 50:0 e $52,5: 22,5$, respectivamente. Isto representa, em média, uma taxa de retorno da ordem de $23,2 \%$ ao ano, a partir de um reajuste de $17,5 \%$ na arroba do bezerro, em relação ao preço da arroba do boi gordo, para lucratividade de $\mathrm{R} \$ 0,053$ por quilo de carne produzida. Quando o índice de correção foi de $20 \%$, a atividade mostrou-se expressivamente atrativa do ponto de vista econômico, notadamente o tratamento com $75 \%$ de concentrado básico, com maior RSCI (35,16\% ao ano). Entretanto, o tratamento com $15 \%$ de cama de frango proporcionou maior lucro por unidade de carne produzida em todos os níveis de reajuste, permitindo menor impacto no valor de venda da carne, quando se optou por menores taxas de retorno, sem, contudo, comprometer a lucratividade.

Comparando os resultados de eficiência técnica, mostrados na Tabela 9, com os de eficiência econômica, no estudo simulado na Tabela 11 e na Figura 2, entre os tratamentos, verifica-se que o melhor desempenho técnico dos animais submetidos ao tratamento 75:0 (75\% de concentrado básico, 0\% de cama de frango e $25 \%$ de volumoso na MS da ração total) não correspondeu à maior eficiência econômi-

Tabela 11 - Simulação na variação do preço do quilo da carne do bezerro e seu efeito na renda bruta e no lucro por bezerro, por quilo de carne produzido e por tratamento

Table 11 - Simulation in the calf meat kilo variation price and its effect in the total income and in the profit per calf, per kilo of meat produced and per treatment

\begin{tabular}{|c|c|c|c|c|c|}
\hline \multirow{2}{*}{$\begin{array}{l}\text { Preço da carne do } \\
\text { bezerro }(\mathrm{R} \$ / \mathrm{kg}) \\
\text { Calf meat price }\end{array}$} & \multirow{2}{*}{$\begin{array}{l}\text { Renda bruta } \\
\text { (R\$) } \\
\text { Total income }\end{array}$} & \multicolumn{2}{|c|}{$\begin{array}{l}\text { Custo total } \\
\text { Total cost }\end{array}$} & \multicolumn{2}{|c|}{$\begin{array}{l}\text { Lucro } \\
\text { Profit }\end{array}$} \\
\hline & & $\begin{array}{l}\text { (R\$/animal) } \\
(R \$ / \text { animal })\end{array}$ & $(\mathrm{R} \$ / \mathrm{kg})$ & $\begin{array}{l}(\mathrm{R} \$ / \text { animal }) \\
(R \$ / \text { animal })\end{array}$ & $(\mathrm{R} \$ / \mathrm{kg})$ \\
\hline & & \multicolumn{4}{|c|}{$\begin{array}{c}\text { Tratamento 50:0 } \\
\text { Treatment 50:0 }\end{array}$} \\
\hline 1,60 & 181,00 & 191,24 & 1,69 & $-10,23$ & $-0,035$ \\
\hline 1,68 & 189,79 & 191,24 & 1,69 & $-1,45$ & $-0,050$ \\
\hline 1,76 & 198,56 & 191,24 & 1,70 & 7,32 & 0,021 \\
\hline 1,84 & 207,34 & 191,24 & 1,70 & 16,10 & 0,042 \\
\hline \multirow[t]{2}{*}{1,92} & 216,12 & 191,24 & 1,70 & 24,88 & 0,060 \\
\hline & & \multicolumn{4}{|c|}{$\begin{array}{c}\text { Tratamento 35:15 } \\
\text { Treatment 35:15 }\end{array}$} \\
\hline 1,60 & 173,00 & 176,32 & 1,62 & $-2,69$ & $-0,01$ \\
\hline 1,68 & 181,99 & 176,32 & 1,63 & 5,68 & 0,019 \\
\hline 1,76 & 190,38 & 176,32 & 1,63 & 14,04 & 0,042 \\
\hline 1,84 & 198,34 & 176,32 & 1,63 & 22,41 & 0,061 \\
\hline \multirow[t]{2}{*}{1,92} & 207,1 & 176,32 & 1,63 & 30,78 & 0,077 \\
\hline & & \multicolumn{4}{|c|}{$\begin{array}{c}\text { Tratamento 75:0 } \\
\text { Treatment } 75: 0\end{array}$} \\
\hline 1,60 & 193,38 & 201,32 & 1,67 & $-7,94$ & $-0,026$ \\
\hline 1,68 & 202,89 & 201,32 & 1,67 & 1,58 & 0,0050 \\
\hline 1,76 & 212,41 & 201,32 & 1,67 & 11,1 & 0,030 \\
\hline 1,84 & 221,93 & 201,32 & 1,67 & 20,61 & 0,050 \\
\hline \multirow[t]{2}{*}{1,92} & 231,45 & 201,32 & 1,67 & 30,13 & 0,068 \\
\hline & & \multicolumn{4}{|c|}{$\begin{array}{c}\text { Tratamento 52,5:22,5 } \\
\text { Treatment 52,5:22,5 }\end{array}$} \\
\hline 1,60 & 177,27 & 190,64 & 1,72 & $-13,37$ & $-0,05$ \\
\hline 1,68 & 185,93 & 190,64 & 1,72 & $-4,71$ & $-0,020$ \\
\hline 1,76 & 194,58 & 190,64 & 1,72 & 3,95 & 0,010 \\
\hline 1,84 & 203,24 & 190,64 & 1,73 & 12,60 & 0,030 \\
\hline 1,92 & 211,89 & 190,64 & 1,73 & 21,26 & 0,050 \\
\hline
\end{tabular}

R. Bras. Zootec., v.31, n.5, p.2055-2069, 2002 
ca, observada no tratamento $35: 15$ (35\% concentrado, $15 \%$ de cama de frango e $50 \%$ de volumoso na MS da ração total). Estes resultados estão de acordo com os observados por Heady \& Dillon (1961), os quais sustentam a hipótese de que as rações que reduzem custos podem não ser necessariamente as mesmas que produzem ganhos de peso mais rápidos. Nesse sentido, Mejía (1995) concluiu que a economicidade das rações deve ser analisada no contexto total dos custos de produção, sendo a ração mais viável a de maior rentabilidade. Portanto, pode-se inferir que, para as condições em que foi conduzido o presente estudo, o tratamento 35:15 representou a melhor alternativa tecnológica para exploração destes animais, pois gerou a melhor relação custo-benefício.

Comportamento semelhante, embora com menor impacto, foi observado entre os tratamentos, quando se avaliaram variações no preço do concentrado, mantendo fixo o preço da carne. Constam da Tabela 12 este cenário e o reflexo nos custos e lucros de

Tabela 12 - Efeito do preço do concentrado no custo de produção e no lucro por bezerro, por unidade de carne produzida e por tratamento

Table 12 - Effect of the concentrate price in the production cost and profit per calf, per unit of produced meat and per treatment

\begin{tabular}{|c|c|c|c|c|c|c|}
\hline $\begin{array}{l}\text { Preço carne } \\
\text { do bezerro } \\
\text { Calf meat price }\end{array}$ & $\begin{array}{c}\text { Preço } \\
\text { Concentrado } \\
\text { Concentrate price }\end{array}$ & $\begin{array}{l}\text { Relação preço } \\
\text { Carne/Conc. } \\
\text { Meat/concentrate } \\
\text { price relationship }\end{array}$ & \multicolumn{2}{|c|}{$\begin{array}{l}\text { Custo total } \\
\text { Total cost }\end{array}$} & \multicolumn{2}{|c|}{$\begin{array}{l}\text { Lucro } \\
\text { Profit }\end{array}$} \\
\hline$(\mathrm{R} \$ / \mathrm{kg})$ & $(\mathrm{R} \$ / \mathrm{kg})$ & $(\mathrm{R} \$ / \mathrm{kg} / \mathrm{R} \$ / \mathrm{kg})$ & (R\$/animal) & $(\mathrm{R} \$ / \mathrm{kg})$ & (R\$/animal) & $(\mathrm{R} \$ / \mathrm{kg})$ \\
\hline \multicolumn{7}{|c|}{ Tratamento 50:0 } \\
\hline 1,60 & 0,26 & 6,15 & 191,24 & 1,69 & $-10,23$ & $-0,035$ \\
\hline 1,60 & 0,25 & 6,40 & 188,02 & 1,66 & $-7,01$ & $-0,024$ \\
\hline 1,60 & 0,24 & 6,67 & 184,84 & 1,63 & $-3,83$ & $-0,013$ \\
\hline 1,60 & 0,23 & 6,96 & 181,67 & 1,61 & $-0,66$ & $-0,002$ \\
\hline 1,60 & 0,22 & 7,27 & 178,49 & 1,58 & 2,52 & 0,009 \\
\hline 1,60 & 0,21 & 7,62 & 175,32 & 1,55 & 5,69 & 0,02 \\
\hline 1,60 & 0,20 & 8,00 & 172,14 & 1,52 & 8,86 & 0,031 \\
\hline \multicolumn{7}{|c|}{$\begin{array}{l}\text { Tratamento } 35: 15 \\
\text { Treatment } 35: 15\end{array}$} \\
\hline 1,60 & 0,26 & 6,15 & 176,32 & 1,62 & $-2,69$ & $-0,01$ \\
\hline 1,60 & 0,25 & 6,40 & 174,06 & 1,60 & $-0,43$ & $-0,002$ \\
\hline 1,60 & 0,24 & 6,67 & 171,80 & 1,58 & 1,84 & 0,007 \\
\hline 1,60 & 0,23 & 6,96 & 169,53 & 1,56 & 4,10 & 0,015 \\
\hline 1,60 & 0,22 & 7,27 & 167,27 & 1,54 & 6,36 & 0,023 \\
\hline 1,60 & 0,21 & 7,62 & 165,00 & 1,52 & 8,63 & 0,031 \\
\hline 1,60 & 0,20 & 8,00 & 162,74 & 1,50 & 10,89 & 0,039 \\
\hline \multicolumn{7}{|c|}{$\begin{array}{c}\text { Tratamento 75:0 } \\
\text { Treatment } 75: 0\end{array}$} \\
\hline 1,60 & 0,26 & 6,15 & 201,32 & 1,67 & $-7,94$ & $-0,026$ \\
\hline 1,60 & 0,25 & 6,40 & 197,24 & 1,63 & $-3,86$ & $-0,012$ \\
\hline 1,60 & 0,24 & 6,67 & 193,26 & 1,60 & 0,22 & 0,001 \\
\hline 1,60 & 0,23 & 6,96 & 189,08 & 1,56 & 4,29 & 0,014 \\
\hline 1,60 & 0,22 & 7,27 & 185,00 & 1,53 & 8,37 & 0,027 \\
\hline 1,60 & 0,21 & 7,62 & 180,93 & 1,50 & 12,45 & 0,040 \\
\hline 1,60 & 0,20 & 8,00 & 176,85 & 1,46 & 16,53 & 0,053 \\
\hline \multicolumn{7}{|c|}{$\begin{array}{c}\text { Tratamento 52,5:22,5 } \\
\text { Treatment 52,5:22,5 }\end{array}$} \\
\hline 1,60 & 0,26 & 6,15 & 190,64 & 1,72 & $-13,37$ & $-0,05$ \\
\hline 1,60 & 0,25 & 6,40 & 187,51 & 1,69 & $-10,24$ & $-0,04$ \\
\hline 1,60 & 0,24 & 6,67 & 184,38 & 1,66 & $-7,11$ & $-0,03$ \\
\hline 1,60 & 0,23 & 6,96 & 181,26 & 1,64 & $-3,98$ & $-0,01$ \\
\hline 1,60 & 0,22 & 7,27 & 178,13 & 1,61 & $-0,86$ & 0 \\
\hline 1,60 & 0,21 & 7,62 & 175,00 & 1,58 & 2,27 & 0,01 \\
\hline 1,60 & 0,20 & 8,00 & 171,88 & 1,55 & 5,39 & 0,02 \\
\hline
\end{tabular}

R. Bras. Zootec., v.31, n.5, p.2055-2069, 2002 
produção decorrentes destas variações. Nota-se que, à medida que se reduz o preço do concentrado de $\mathrm{R} \$ 0,26$ para $\mathrm{R} \$ 0,20$, aumenta a relação entre o preço da carne e o preço do concentrado de 6,15:1 para $8,0: 1$, reduzindo os custos e proporcionando lucros crescentes a partir da relação 6,67:1 para os tratamentos 35:15 e 75:0; 7,27:1 para o tratamento 50:0; e 7,62:1 para o tratamento 52,5:22,5. Verifica-se, portanto, maior impacto na redução dos custos, com maior incremento na lucratividade para o tratamento com $75 \%$ de concentrado básico, cuja participação do concentrado na ração total ocorre em maior proporção, aliado ao fato da maior quantidade de unidade de carne disponível para comercialização.

O comportamento do retorno sobre o capital investido decorrente da variação do preço do concentrado apresentado na Figura 3, demonstra maior sensibilidade na amplitude de variação das taxas de retorno para os tratamentos 75:0 e 35:15, com maior e menor proporção de concentrado na matéria seca da ração total $(75$ e $35 \%)$, respectivamente. No tratamento com $75 \%$ de concentrado básico, quando a relação entre os preços foi de 8:1, obteve-se RSCI atrativo, sendo cerca de 51,8\% superior à média de retorno dos outros tratamentos. Presume-se, portanto, que, em confinamento com elevado nível nutricional,

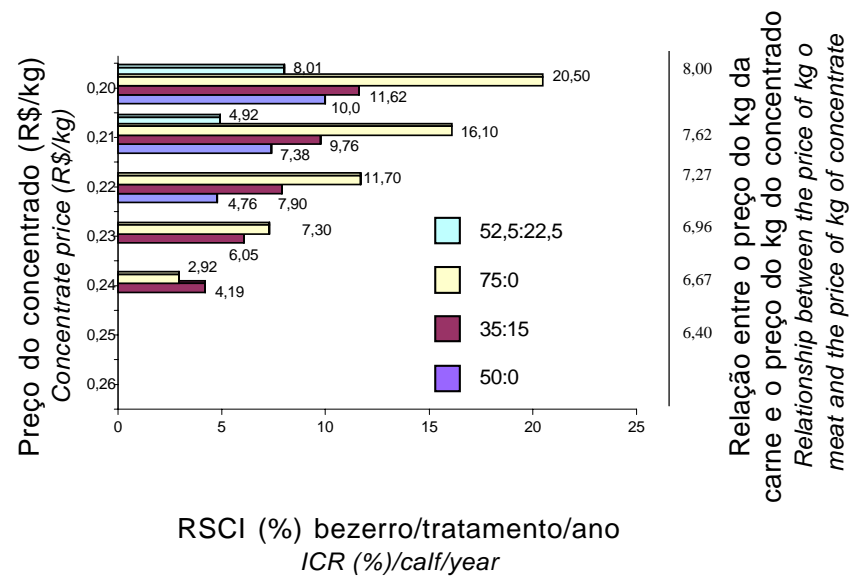

Figura 3 - Variação no preço do quilo do concentrado, relação entre o preço do quilo de carne e o preço do quilo do concentrado e retorno sobre o capital investido.

Figure 3 - Variation in the price of $\mathrm{kg}$ of concentrate, relation between the price of kilo of meat and the price of kilo of concentrate and return on the invested capital. o preço do concentrado constitui-se em importante parâmetro de aferição econômica, visto que o impacto nos custos variáveis e a viabilidade do empreendimento são de grande magnitude.

Por outro lado, para os tratamentos 50:0 e 52,5:22,5, com 50 e $52,5 \%$ de concentrado na matéria seca da ração total, a redução no preço do concentrado de $\mathrm{R} \$ 0,26$ para $\mathrm{R} \$ 0,23(11,5 \%$ ) e de $\mathrm{R} \$ 0,26$ para $\mathrm{R} \$ 0,22$ $(15,4 \%)$, respectivamente, cuja relação entre os custos foi de 6,15 a $6,96: 1$ no primeiro caso e de 6,15 a 7,27:1 no segundo, não foi suficiente para remunerar o capital investido. Entretanto, embora com menor impacto a partir de 15,4 e 19,2\% na redução do preço do concentrado, as taxas de retorno para os respectivos tratamentos foram positivas, embora modestas.

\section{Conclusões}

Os custos operacionais efetivos em ordem de importância são: alimentação (concentrado, cama de frango e capim-elefante), custo do bezerro, mão-de-obra, produtos veterinários, energia, reparos e impostos.

A análise econômica indica lucro negativo, quando o preço de venda da carne produzida é igual ao preço de carne do boi gordo. Acréscimos a partir de 15\% acima do valor referência do boi gordo apontam a tecnologia gerada como uma atividade economicamente viável, com a utilização de $15 \%$ de cama de frango na dieta total, como alternativa tecnológica que apresenta a melhor relação custo benefício.

Mercado, pagamento diferenciado, escala de produção e estratégias de manejo alimentar constituem parâmetros indispensáveis ao estudo de viabilidade econômica para adoção desse sistema de produção.

\section{Literatura Citada}

ANUALPEC 2000. Anuário da pecuária brasileira. São Paulo: FNP Consultoria \& Comércio. 392p.

ARAÚJO, G.G.L.; SILVA, J.F.C.; VALADARES FILHO, S.C. et al. Ganho de peso, conversão alimentar e característica da carcaça de bezerros alimentados com dietas contendo diferentes níveis de volumoso. Revista Brasileira de Zootecnia, v.27, n.5, p.1006-1012, 1998.

CAMPOS, O.F.; LIZIEIRE, R.S.; SPALLA, R.G. Experimento do CNPGL/EMBRAPA com abate de machinhos da raça holandesa aos 6 meses de idade apresenta bons resultados. Gado Holandês, n.451, p.36-45, 1996.

FERREIRA, M.A.; VALADARES FILHO, S.C.; SILVA, J.F.C. et al. Consumo, conversão alimentar, ganho de peso e características de carcaça de bovinos F1 Simental x Nelore. Revista Brasileira de Zootecnia, v.28, n.2, p.343-351, 1999. 
GOMES, S.T.; NOVAES, L.P. Custo da produção de leite C - Estado de São Paulo. Brasília: SNPA/Ministério da Agricultura e Reforma Agrária/EMBRAPA/CNPGL, SAA/CPA/ IZ, FAESP/ABPLB, 1992. 59p.

HEADY, E.O.; DILLON, J.L. Agricultural production functions. Iowa: Iowa State College Press-Ames, 1961. $667 p$.

MATSUNAGA, M.; BEMELMANS, P.F.; TOLEDO, P.E.N. et al. Metodologia de custo de produção utilizado pelo IEA. Agricultura em São Paulo, v.23, n.1, p.123-39, 1976.

MEJÍA, J.M.J. Análise da eficiência técnica e econômica do uso de farelo de gérmen de milho no desaleitamento precoce de bezerros. Viçosa, MG: Universidade Federal de Viçosa, 1995. 108p. Dissertação (Mestrado em Zootecnia) Universidade Federal de Viçosa, 1995.

NATIONAL RESERARCH COUNCIL - NRC. Nutrient requirements of dairy cattle. 6.ed. Washington, D.C.: National Academy Press, 1989. 157p.

REIS, C.S. Utilização do capim elefante (Pennisetum Purpureum Schum. cv. Mineiro), submetido à adubação química e orgânica, na alimentação de vacas leiteiras. Viçosa, MG: Universidade Federal de Viçosa, 2000. 106p. Dissertação (Mestrado em Zootecnia)- Universidade Federal de Viçosa, 2000.
RIBEIRO, T.R. Desempenho e qualidade de carcaça de bezerros holandeses alimentados com dietas contendo diferentes níveis de concentrado. Viçosa, MG: Universidade Federal de Viçosa, 1997. 89p. Dissertação (Mestrado em Zootecnia) - Universidade Federal de Viçosa, 1997.

SIGNORETTI, R.D.; SILVA, J.F.C.; VALADARES FILHO, S.C. et al. Crescimento, conversão alimentar e rendimento de carcaça de bezerros da raça holandesa alimentados com dietas contendo diferentes níveis de volumoso. Revista Brasileira de Zootecnia, v.28, n.1, p.185-194, 1999.

Recebido em: 18/12/01

Aceito em: 07/06/02 